\title{
Antithrombotic therapy after mitral valve repair: VKA or aspirin?
}

\author{
Sake J. van der Wall ${ }^{1}$. Jules R. Olsthoorn ${ }^{2}$. Samuel Heuts ${ }^{2} \cdot$ Robert J. M. Klautz $^{3}$ - Anton Tomsic ${ }^{3}$ - Evert K. Jansen ${ }^{4}$. \\ Alexander B. A. Vonk ${ }^{4} \cdot$ Peyman Sardari $\mathrm{Nia}^{2} \cdot$ Frederikus A. Klok ${ }^{1} \cdot$ Menno V. Huisman ${ }^{1}$
}

Published online: 21 August 2018

(c) The Author(s) 2018, Corrected publication September/2018

\begin{abstract}
The optimal antithrombotic therapy following mitral valve repair (MVr) is still a matter of debate. Therefore, we evaluated the rate of thromboembolic and bleeding complications of two antithrombotic prevention strategies: vitamin K antagonists (VKA) versus aspirin. Consecutive patients who underwent MVr between 2004 and 2016 at three Dutch hospitals were evaluated for thromboembolic and bleeding complications during three postoperative months. The primary endpoint was the combined incidence of thromboembolic and bleeding complications to determine the net clinical benefit of VKA strategy as compared with aspirin. Secondary objectives were to evaluate both thromboembolic and bleeding rates separately and to identify predictors for both complications. A total of 469 patients were analyzed, of whom 325 patients (69\%) in the VKA group and 144 patients (31\%) in the aspirin group. Three months postoperatively, the cumulative incidence of the combined end point of the study was 9.2\% (95\% CI 6.1-12) in the VKA group and 11\% (95\%CI 6.0-17) in the aspirin group [adjusted hazard ratio (HR) 1.6, 95\%CI 0.83-3.1]. Moreover, no significant differences were observed in thromboembolic rates (adjusted HR 0.82, 95\% CI 0.16-4.2) as well as in major bleeding rates (adjusted HR 1.89, 95\%CI 0.90-3.9). VKA and aspirin therapy showed a similar event rate of $10 \%$ during 3 months after MVr in patients without prior history of AF. In both treatment groups thromboembolic event rate was low and major bleeding rates were comparable. Future prospective, randomized trials are warranted to corroborate our findings.
\end{abstract}

Keywords Mitral valve repair $\cdot$ Mitral valve annuloplasty $\cdot$ Antithrombotic therapy $\cdot$ Thromboembolism $\cdot$ Bleeding

\section{Highlights}

- The appropriate antithrombotic therapy following $\mathrm{MVr}$ is still a subject of controversy

- Consecutive patients who received either VKA or aspirin strategy were evaluated for thromboembolic and bleeding complications occurring within three months after $\mathrm{MVr}$

Sake J. van der Wall

s.j.van_der_wall@lumc.nl

1 Department of Thrombosis and Hemostasis, Leiden University Medical Centre, Albinusdreef 2, 2300 RC Leiden, The Netherlands

2 Department of Cardio-Thoracic Surgery, Maastricht University Medical Centre, Maastricht, The Netherlands

3 Department of Cardio-Thoracic Surgery, Leiden University Medical Centre, Leiden, The Netherlands

4 Department of Cardio-Thoracic Surgery, VU University Medical Centre, Amsterdam, The Netherlands
- VKA and aspirin therapy showed a similar event rate of $10 \%$ during the first three months after MVr in patients without prior history of AF

- The choice of antithrombotic treatment should be individualized based on patient-specific considerations, such as risk factors for AF, compliance with treatment and frailty

\section{Introduction}

Mitral valve repair (MVr) is recognized as the gold standard for degenerative mitral regurgitation. Compared to mitral valve replacement, repair results in improved survival, better preservation of postoperative left ventricular function and avoidance of the need for long-term anticoagulation treatment $[1,2]$. The risk of thromboembolic events following MVr varies from 0.4 to $1.6 \%$ per year, and reaches $2.5 \%$ during the first postoperative month, even with routine anticoagulation therapy [3, 4]. However, the appropriate 
antithrombotic therapy following MVr is still a subject of controversy. Recommendations from international guidelines for the postoperative antithrombotic management have been controversial [5-7], and are based on observational studies without conclusive results, or are provided without references supporting the recommendation [4, 8-11].

Consequently, antithrombotic prophylaxis for the prevention of thrombotic events early after $\mathrm{MVr}$ varies widely among cardio-thoracic surgeons with a vitamin $\mathrm{K}$ antagonist (VKA) prescription varying from 46 to $64 \%$ in patients with sinus rhythm $[12,13]$. The risk of thromboembolism secondary to a high incidence of new onset atrial fibrillation (AF) postoperatively and the thrombogenic tendency of the nonendothelialized repair components could motivate surgeons and cardiologists to prescribe VKA therapy for the first months after MVr [14]. However, evidence is limited and more accurate knowledge of the postoperative antithrombotic treatment is required. Based on recent literature and anecdotal reports, we hypothesized that VKA treatment is associated with an increased risk of major bleeding events and no reduction in thromboembolic events [18].

We set out to perform a retrospective observational study to evaluate the rate of thromboembolic and bleeding and complications of two antithrombotic prevention strategiesone with VKA and one with aspirin-occurring within the first three postoperative months.

\section{Materials and methods}

\section{Study design and patients}

This study was a retrospective observational multicentre cohort study of consecutive adult patients who underwent $\mathrm{MVr}$, to evaluate thromboembolic and bleeding complications of two antithrombotic strategies, VKA and aspirin. Data were collected from the databases of the departments of cardiothoracic surgery of the Leiden University Medical Centre (LUMC), VU University medical centre (VUmc) and Maastricht University Medical Centre (MUMC). Patients who underwent a first $\mathrm{MVr}$ with or without concomitant tricuspid valve repair (TVr) between 2004 and 2016 in these three centres were eligible. The post-operative care of these patients often took place in one of 16 affiliated regional hospitals, in which all postoperative medical files were scrutinized for primary and secondary endpoints. Patients were excluded when they underwent other concomitant cardiac procedures than $\mathrm{TVr}$, had previous cardiac surgery or were diagnosed with AF preoperatively. Other concomitant procedures were excluded because these lead to more heterogeneous patient groups. The institutional review board of the LUMC, VUmc and MUMC approved the study protocol and waived the need for informed consent due to the observational design.

\section{Procedures and treatment}

$\mathrm{MVr}$ was performed at the department of cardiothoracic surgery at the LUMC, VUmc or MUMC and involved implantation of an annuloplasty ring (Edwards Physio I or II mitral ring, Carpentier-Edwards Classic Annuloplasty Ring or Duran AnCore Ring for MVr, and Edwards MC3 tricuspid ring or Carpentier-Edwards Classic Annuloplasty Ring in case of concomitant TVr, Edwards Lifesiences/Medtronic, USA), and various concomitant techniques (leaflet resections, artificial chorda tendinae implant, chordal transposition, or edge-to-edge technique).

Group A comprised patients from the LUMC and VUmc hospitals, in which therapeutic doses of low-molecularweight heparin (LMWH) nadroparin were given on the first postoperative day at $7600 \mathrm{IU} /$ day for patients $<50 \mathrm{~kg}$, $11.400 \mathrm{IU} /$ day for patients $50-70 \mathrm{~kg}, 15.200 \mathrm{IU} /$ day for patients $70-100 \mathrm{~kg}$ and $19.000 \mathrm{IU} /$ day for patients $>100 \mathrm{~kg}$ simultaneously with VKA. Treatment with nadroparin was continued until a VKA reached therapeutic levels, as shown by an international normalized ratio (INR) $>2.0$ on two consecutive days. VKA therapy was maintained for 6-12 weeks postoperatively and then discontinued at the discretion of the referring cardiologist and occasionally switched to aspirin. The target INR during VKA treatment was 2.0-3.0.

Group B consisted of patients from the MUMC hospital, in which prophylactic doses of nadroparin were started on the first postoperative day at $3750 \mathrm{IU} /$ day for patients $<80 \mathrm{~kg}, 5700 \mathrm{IU} /$ day for patients $80-100 \mathrm{~kg}$ and $7600 \mathrm{IU} /$ day for patients $>100 \mathrm{~kg}$ simultaneously with aspirin $80 \mathrm{mg}$ once daily which was continued lifelong in patients with sinus rhythm. Nadroparin was stopped as soon as the patient was fully mobilized. In case of postoperative new onset AF that sustained for more than $24 \mathrm{~h}$, nadroparin and VKA were started analogous to the antithrombotic strategy used in the LUMC and VUmc.

\section{Study endpoints}

The primary endpoint of this study was the combined incidence of thromboembolic and major bleeding complications 3 months following MVr. This double endpoint was the basis for determining the net clinical benefit of VKA as compared with aspirin. Since we anticipated a high incidence of postoperative new onset AF, we also compared the primary endpoint in patients who did not develop AF during follow-up as well as in patients who received treatment according to the preferred strategy.

Secondary objectives were to evaluate the incidence rates of thromboembolic and major bleeding events separately and 
to identify predictors for bleeding and thrombotic complications. All thromboembolic and bleeding events were classified using the criteria for reporting mortality and morbidity after cardiac valve interventions respectively and those of the International Society on Thrombosis and Haemostasis respectively $[15,16]$. Thromboembolic and bleeding complications occurring on the first postoperative day were not taken into consideration because both antithrombotic therapies were started this day. All suspected bleeding events were independently adjudicated by two expert physicians (F.K. and M.V.) who were blinded to treatment assignment. Disagreement was resolved by consensus.

Predefined candidate predictors for thromboembolic and bleeding events were defined according to the documentation provided by the treating physician, e.g. age, sex, prior arterial or venous thromboembolism, prior PCI, hypertension, history of smoking, preoperative use of anticoagulation therapy, left ventricular ejection fraction (LVEF), concomitant TVr, repeat thoracotomy and new onset AF. The cause of death was verified by reviewing the pathology report. In case autopsy had not been performed, the likely cause of death was verified with the treating physician. All patients were followed and censored at a maximum follow up period of 3 months, the date of last chart documentation, reoperation or outcome events, whichever came first.

\section{Statistical analyses}

Means (standard deviation [SD]) and medians (interquartile range [IQR]) to present baseline continuous baseline variables were used. For categorical variables, frequencies and percentages were used. Pearson's $\chi^{2}$ test was used to compare the distribution of categorical variables, whereas the independent $t$-tests were used for normally distributed continuous variables. For analysis of primary and secondary objectives, cumulative incidences of bleeding and thromboembolic events of both antithrombotic strategies were estimated according to the Kaplan-Meier methods and presented with two-sided 95\% confidence intervals (CI). A Cox proportional hazard model was used to compare both strategies, adjusted for age, gender, and baseline differences.

Backward conditional multivariate Cox-regressions analysis was used to evaluate possible predictors for thrombotic and bleeding events, using variables of clinical importance (age and gender) or that were identified to be relevant predictors $(\mathrm{P}<0.1)$ in univariate analysis. Data were analyzed using SPSS version 23 (SPSS, Chicago, IL, USA). A $P$-value below 0.05 was considered to be significant.
Table 1 Baseline characteristics of 469 patients who underwent $\mathrm{MVr}$

\begin{tabular}{lll}
\hline Patient characteristics & $\begin{array}{l}\text { Group } \\
\text { A: VKA } \\
(\mathrm{n}=325)\end{array}$ & $\begin{array}{l}\text { Group B: } \\
\text { aspirin } \\
(\mathrm{n}=144)\end{array}$ \\
\hline Age at operation, mean \pm SD & $60 \pm 13$ & $62 \pm 11$ \\
Male, $\mathrm{n}(\%)$ & $195(60)$ & $85(59)$ \\
Prior ischemic stroke, n (\%) & $7(2.2)$ & $8(5.6)$ \\
Prior MI, n (\%) & $12(3.7)$ & $4(2.8)$ \\
Prior PCI, n (\%) & $11(3.4)$ & $5(3.5)$ \\
Prior VTE, n (\%) & $11(3.5)$ & $2(2.6)$ \\
LV ejection fraction <40\%, n (\%) & $12(3.8)$ & $13(9)^{*}$ \\
Diabetes, $\mathrm{n}(\%)$ & $17(5.4)$ & $5(3.5)$ \\
Hypertension, $\mathrm{n}(\%)$ & $149(47)$ & $74(51)$ \\
COPD, n (\%) & $29(8.9)$ & $15(10)$ \\
History of smoking, n (\%) & $99(31)$ & $27(19)$ \\
Preoperative anticoagulation use, n (\%) & & \\
VKA & $12(3.7)$ & $4(2.8)$ \\
Aspirin & $57(18)$ & $39(27)^{*}$ \\
Clopidogrel & $3(0.90)$ & $2(1.4)$ \\
Dual AP & $1(0.30)$ & $2(1.4)$ \\
Active endocarditis at the moment of & $24(7.4)$ & $9(6.3)$ \\
surgery, n $(\%)$ & $72(22)$ & $7(4.9)^{*}$ \\
Concomitant TVr, n (\%) & & \\
\hline
\end{tabular}

$S D$ standard deviation, $M I$ myocardial infarction, $P C I$ percutaneous coronary intervention, $V T E$ venous thromboembolic event, $L V$ left ventricular, $V K A$ vitamin $\mathrm{K}$ antagonist, $A P$ antiplatelet, $T V r$ tricuspid valve repair

*P-value below 0.05

\section{Results}

\section{Patients}

In the three participating cardiothoracic surgical centers, 809 patients underwent a first isolated MVr between 2004 and 2016. Of these patients, 340 (42\%) were excluded for the following reasons: 109 did not receive treatment in one of the affiliated regional hospitals postoperatively (4.9\%), 224 had preoperative $\mathrm{AF}(10 \%)$ and seven patients were lost to follow up $(0.32 \%)$. The remaining $469(21 \%)$ patients were included; 325 patients (69\%) in group A and 144 patients (31\%) in group B. The baseline characteristics of both groups are shown in Table 1. Their mean age was 61 (SD 12) and 280 patients $(60 \%)$ were men. Patients in group A underwent concomitant TVr more frequently (22\% vs. $4.9 \%$ ). In group B, a LVEF below $40 \%$ and preoperative aspirin use were more present (9\% vs. $3.8 \%$ and $27 \%$ vs. $18 \%$ respectively). A total of 220 patients (47\%) developed new onset AF after surgery and 35 patients $(7.5 \%)$ required a repeat thoracotomy. 


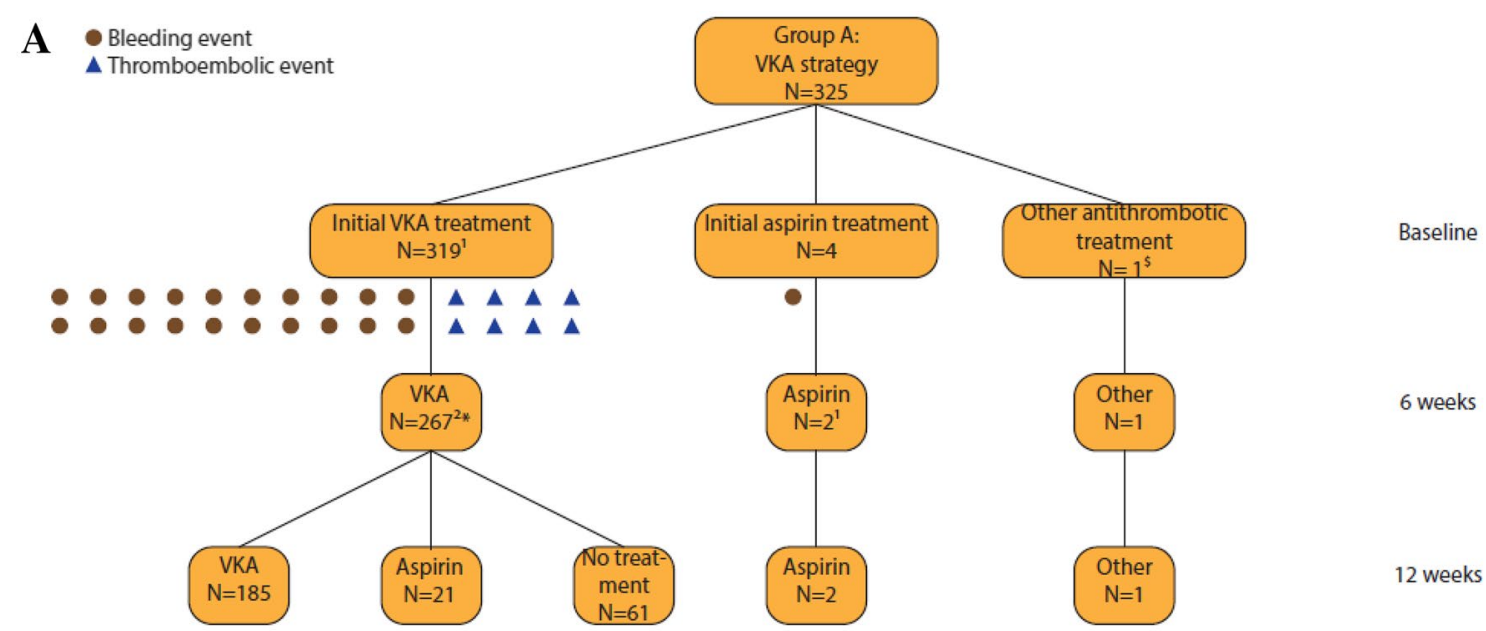

B

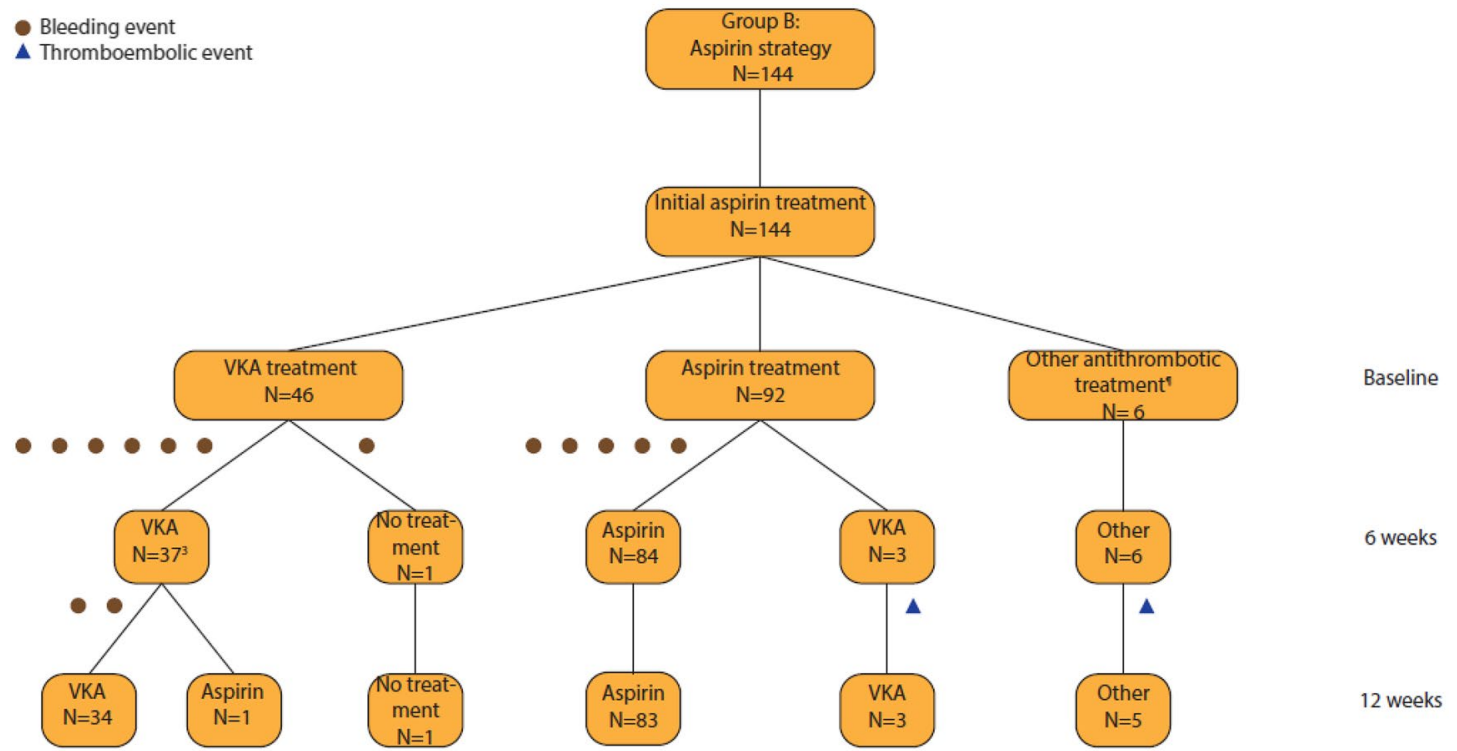

Fig. 1 Flowchart of medication use and events of group A: VKA (a) group B: aspirin (b). ${ }^{1} 1,{ }^{2} 8,{ }^{3} 1$ patients censored for other reasons than study endpoints. $*$ Data missing in 16 patients. ${ }_{2} 2$ patients treated

\section{Antithrombotic treatment}

Of the 325 patients in group A, 319 patients (98\%) were treated with VKA therapy, four (1.2\%) with aspirin therapy and one patient (0.31\%) with LMWH (Fig. 1a). In group B, 92 of the 144 patients (64\%) received aspirin, 46 patients (32\%) VKA because of new onset AF and six patients (4.2\%) received other antithrombotic therapy than VKA or aspirin (Fig. 1b). Twenty-three patients (25\%) in group B, who with direct oral anticoagulant (DOAC), 4 patients with clopidogrel, "1 patient treated with low-molecular-weight heparin

received initial aspirin therapy, experienced a single episode of new onset AF.

\section{VKA versus ASA}

Table 2 shows the incidence of thromboembolic and bleeding events in each study group. The primary end point of the study - the composite of thromboembolic and bleeding events-was reached in 29/325 patients in group A 
Table 2 Clinical outcomes within 3 months after MVr

\begin{tabular}{lll}
\hline Bleeding events & $\begin{array}{l}\text { Group A: VKA } \\
(\mathrm{N}=325)\end{array}$ & $\begin{array}{l}\text { Group B: } \\
\text { aspirin } \\
(\mathrm{N}=144)\end{array}$ \\
\hline $\begin{array}{l}\text { Major bleeding } \\
\text { Site }\end{array}$ & $21(6.8)^{\mathrm{a}}$ & $14(9.1)$ \\
$\quad$ Chest & 20 & 12 \\
$\quad$ GI tract & 0 & 1 \\
Unknown & 1 & 1 \\
Fatal bleeding & 1 & 1 \\
Thromboembolic events & $8(2.6)$ & $2(1.6)$ \\
Type & & 1 \\
Ischemic stroke & 4 & 0 \\
TIA & 4 & 1 \\
Left atrial thrombus & 0 & 1 \\
Fatal ischemic stroke & 0 & \\
\hline
\end{tabular}

GI gastrointestinal, TIA transient ischemic attack, MI myocardial infarction, $D V T$ deep venous thrombosis

${ }^{a}$ Numbers in parenthesis are cumulative incidence

(cumulative incidence 9.2\%, 95\%CI 6.1-12) and in 16/144 patients in group B (cumulative incidence $11 \%, 95 \% \mathrm{CI}$ 6.0-17; adjusted hazard ratio (HR): $1.6,95 \%$ CI 0.83-3.1). The composite of thromboembolic and bleeding events in patients without new onset AF occurred in 14/177 patients (cumulative incidence $8.2 \%, 95 \% \mathrm{CI} 4.1-12$ ) in group A and $5 / 72$ patients in group $\mathrm{B}$ (cumulative incidence $8.1 \%$, 95\% CI 2.0-14.2; adjusted HR 0.97, 95\% CI 0.32-2.9). In patients who received initial treatment according to the preferable strategy, 28/319 patients experienced the primary endpoint in group A and 6/92 patients in group B during the first 3 months, for a cumulative incidence of $9.0 \%$ (95\% CI 5.9-12) and 6.6\% (95\%CI 1.5-12) respectively (adjusted HR $0.90,95 \%$ CI: 0.35-2.3).

\section{Thromboembolism and bleeding}

A total of $8 / 325$ thromboembolic events occurred in group A after a median duration of 9 days (IQ 3.3-15) and $2 / 144$ in group $B$ after a median duration of 50 days (IQR 45-50), for a respective cumulative incidence of $2.6 \%$ (95\% CI 0.84-4.4) and 1.6\% (95\%CI 0-3.8; adjusted HR 0.82, 95\%CI 0.16-4.2). 21/325 patients experienced a major bleeding in group A after a median duration of 12 days (IQR 8-15) and 14/144 patients in group B after a median duration of 11 days (IQR 4.8-20), for cumulative incidences of $6.8 \%(95 \% \mathrm{CI} 4.1-9.5)$ and $9.1 \%(95 \% \mathrm{CI}$ 4.2-14) respectively (adjusted HR 1.89, 95\% CI 0.90-3.9). A total of $89 \%$ of the major bleeding events were pericardial tamponades, of which two were fatal (one in each group).

\section{Other observations}

During the study period, four patients died (cumulative incidence $0.9 \%, 95 \%$ CI 0-1.9), of whom two died in group A and two in group B. Causes of death were pericardial tamponades (two patients), ischemic stroke and cardiac arrest.
Table 3 Predictors for major bleeding and thromboembolic events in 469 patients who underwent $\mathrm{MVr}$

\begin{tabular}{|c|c|c|c|c|}
\hline \multirow[t]{2}{*}{ Predictor } & \multicolumn{2}{|l|}{ Major bleeding } & \multicolumn{2}{|l|}{$\mathrm{TE}$} \\
\hline & Univariate RR (95\%CI) & $\begin{array}{l}\text { Multivariate } \\
\text { RR }(95 \% \text { CI })\end{array}$ & Univariate RR (95\%CI) & $\begin{array}{l}\text { Multivariate } \\
\text { RR }(95 \% \mathrm{CI})\end{array}$ \\
\hline Age $>60$ & $0.94(0.48-1.8)$ & & $0.71(0.21-2.4)$ & \\
\hline Female & $1.2(0.64-2.4)$ & & $0.37(0.78-1.7)$ & \\
\hline Prior ischemic stroke & - & & $3.1(0.39-25)$ & \\
\hline Prior MI & $0.84(0.12-6.1)$ & & - & \\
\hline Prior PCI & $0.80(0.11-5.8)$ & & - & \\
\hline Prior VTE & $1.1(0.15-8.0)$ & & - & \\
\hline LV ejection fraction $<40 \%$ & $2.2(0.78-6.3)$ & & - & \\
\hline Diabetes & $1.9(0.59-6.3)$ & & - & \\
\hline Hypertension & $1.2(0.62-2.3)$ & & $2.3(0.61-9.1)$ & \\
\hline History of smoking & $0.78(0.36-1.7)$ & & $1.5(0.46-5.3)$ & \\
\hline New onset AF & $1.7(0.88-3.4)$ & & $1.1(0.33-4.0)$ & \\
\hline Concomitant TVr & $2.8(1.4-5.7)^{*}$ & $2.8(1.4-5.7)^{*}$ & $2.3(0.59-8.9)$ & \\
\hline Active endocarditis & $1.7(0.6-4.8)$ & & $1.5(0.19-11)$ & \\
\hline
\end{tabular}

$M I$ myocardial infarction, $P C I$ percutaneous coronary intervention, $V T E$ venous thromboembolic event, $L V$ left ventricular, $A F$ atrial fibrillation, $T V r$ tricuspid valve repair

*P-value below 0.05 


\section{Predictors for thromboembolism and major bleeding}

Uni- and multivariate analysis of predictors for thromboembolic and major bleeiding events in patients who received initial treatment according to antithrombotic strategy are shown in Table 3. Multivariate analysis revealed that only concomitant $\mathrm{TVr}$ was independently associated with an increased risk of bleeding events (odds ratio (OR) $2.8,95 \%$ CI 1.4-5.7) for both groups. For thromboembolic events, no independent predictors were found by multivariate analysis.

\section{Discussion}

VKA and aspirin therapy showed a similar event rate of $10 \%$ during the first 3 months after MVr in patients without prior history of AF. In both treatment groups thromboembolic event rate was low and major bleeding rates were comparable.

Nearly all bleedings occurred soon after surgery, particularly during the first 2 weeks after MVr. Interestingly, most of these were pericardial tamponades that required repeat thoracotomy. In contrast, the thromboembolic events occurred more dispersed throughout the first 3 months.

\section{VKA versus aspirin treatment}

We chose a primary combined endpoint of thromboembolic and bleeding rates because both events would have a comparable prognostic effect as both represent an important cause of death and disability after heart valve surgery [17]. A comparison between VKA strategy (group A) and aspirin strategy (group B) revealed no difference in the combined outcome of thromboembolic and bleeding complications as well as for both outcomes separately occurring within 3 months after MVr. As expected, a third of the patients in group B could not follow the aspirin strategy because of new onset $\mathrm{AF}$ and received VKA treatment instead of aspirin therapy. Both of these group B treatment groups experienced major bleeding events to a similar extent. However, after exclusion of AF patients in the entire study population as well as analysing patients who received treatment according to the preferable strategy, again no difference in the combined endpoint was found, despite a group B population with solely aspirin use. Of note, three thromboembolic events in the VKA group occurred within the first 4 days during which VKA treatment still had not yet reached therapeutic levels. The observed 3-month cumulative incidence for thromboembolic events is in aligned with those reported by previous studies [4, 18]. The observed incidence of major bleeding events was slightly higher than described in previous reports, probably due to the adjudication process of postoperative pericardial tamponade $[19,20]$. Pericardial effusion alongside signs of hemodynamic instability was adjudicated as a pericardial bleeding, whereas these events might not be considered as (major) bleedings in previous studies.

\section{Perspective of international guidelines}

Recommendations from international guidelines are contradictory to our results, favouring either VKA or aspirin as postoperative thromboprophylaxis 3 months after $\mathrm{MVr}$ $[5,6,21]$. Three former retrospective studies have compared antiplatelet with anticoagulation therapy in patients after $\operatorname{MVr}[8,19,20,22]$. Two studies found no differences in stroke and bleeding rate of early VKA treatment compared with aspirin therapy, suggesting that VKA treatment might not be necessary [20,22]. The largest study to date by Paparella et al. [19] found less bleeding and comparable arterial thromboembolic events in patients treated with aspirin 6 months following MVr. However, in contrast to our study, no data on $\mathrm{AF}$ were reported and assigned treatment was mainly chosen by the surgeons' preference. A small study by Aramendi et al. [8]. found a beneficial effect of antiplatelet therapy in preventing thromboembolic events compared with VKA treatment with no increased risk of bleeding. Thus, these four studies suggest aspirin use after MVr. This contradicts the recommendation of VKA use over aspirin by the American College of Cardiology/American Heart Association (ACC/AHA) and European Society of Cardiology/European Association of Cardiothoracic Surgery (ESC/EACTS) guidelines [6, 21]. The ACC/AHA recommendations are based on one observational cohort study which found a high 30-day ischemic stroke incidence of $1.5 \%$, despite VKA treatment $[4,21]$. The ESC recommendation is provided without references, illustrating the paucity of information [6]. Since recommendations from guidelines are based on retrospective and underpowered studies, the optimal thromboprophylaxis after MVr remains controversial and a frequent matter of debate. However, based on the scarcity of data, our results might suggest a reassessment of the recommendations from international guidelines.

\section{Predictors}

In our study, only concomitant $\mathrm{TVr}$ was found to be an independent predictor for major bleeding events. Concomitant TVr might have been a more difficult procedure with prolonged cardiopulmonary bypass duration, leading to dysfunction of platelets, which is associated with major cause of excessive bleeding in the early postoperative period [23, 24]. Other not predefined predictors, such as surgery duration, preoperative hematologic laboratory values and surgical 
techniques might also have contributed to the occurrence of early bleeding events. Consistently with earlier findings, no independent predictors were found for thromboembolic events [18].

\section{Clinical perspective}

When considering the appropriate antithrombotic treatment after $\mathrm{MVr}$, the thrombotic risk secondary to the endothelialization process and new onset AF could be a good rationale for physicians to prescribe VKA treatment. During the first three postoperative months, the exposure of circulating blood to non-endothelialized repair components can cause thrombus formation and even endocarditis, particularly due to a relatively slower blood flow in the left atrium compared to other parts of the heart. AF is a common postoperative cardiac arrhythmia after MVr occurring in approximately $24-35 \%$ of the patients, even after two postoperative weeks $[14,25]$. In this study we found this incidence of new onset AF to be $47 \%$. VKA treatment, however, has many disadvantages, including need for frequent laboratory monitoring, variability of dose response and drug and food interactions while in contrast aspirin does not require monitoring and dosage adjustments. Consequently, for practical reasons, aspirin might be preferable as antithrombotic treatment compared to VKA in patients with sinus rhythm. Therefore, the choice of antithrombotic treatment in patients without prior history of AF should be individualized based on patient-specific considerations, such as risk factors for AF, compliance with treatment and frailty. Despite the lack of prospective studies specifically evaluating treatment with direct oral anticoagulants (DOACs) in patients with mitral valve repair, subanalysis of DOAC AF trails have showed a similar overall efficacy and safety as compared with VKA in patients with valvular heart disease, including mitral valve repair [26]. However, international guidelines do not recommend the use of DOACs during the first three to six postoperative months in patients with AF [5-7].Future prospective randomized trials are warranted to provide conclusive results about DOAC treatment in the early postoperative phase after mitral valve repair in patients with and without AF.

\section{Strengths and limitations}

The strength of this study is the large cohort of consecutive patients providing novel and clinically relevant data on the antithrombotic strategy after MVr. Moreover, the study population was rather homogeneous, due to the exclusion of concomitant procedures that might lead to different patient groups (i.e. AF, other valve and coronary atherosclerotic surgery).
Our study had several limitations as well. First, a direct comparison between patients treated with VKA and aspirin would have been preferable but the high incidence of AF makes such a trial difficult to perform. A large number of patients would be required, in particular patients receiving aspirin. Second, antithrombotic treatment was not randomly allocated due to the retrospective study design. Third, no data was available on individual INR measurements and thus the time during which VKA treated patients were in therapeutic range is unclear. Fourth, we performed a multicentre study with inherent perioperative variabilities. Ideally, future prospective, randomized clinical trials are warranted to provide evidence-based recommendations for the implementation of appropriate antithrombotic strategy after MVr.

VKA and aspirin therapy showed a similar event rate of $10 \%$ during 3 months after MVr in patients without prior history of AF. In both treatment groups thromboembolic event rate was low and major bleeding rates were comparable. Future prospective, randomized trials are warranted to corroborate our findings.

Acknowledgements The authors would like to acknowledge the help received from the affiliated hospitals (i.e. Zaandam Medical Centre, Noordwest hospital Alkmaar, Spaarne hospital Haarlem, Haaglanden Medical Centre, Alrijne hospital Leiden, Maasstad hospital Rotterdam, Franciscus Vlietland hospital Rotterdam, Laurentius hospital Roermond, Zuyderland hospital Heerlen/Sittard, and VieCuri Medical Centre Venlo) who contributed to data retrieval. We are also grateful to prof. Suzanne Cannegieter (Department of Clinical Epidemiology, Leiden University Medical Centre, the Netherlands) for her help in analyzing the data.

\section{Compliance with Ethical Standards}

Conflict of interest Frederikus A. Klok reports research grants from Bayer, Bristol-Myers Squibb, Boehringer-Ingelheim, Daiichi-Sankyo, MSD and Actelion. Menno V. Huisman reports research grants from ZONMW, Pfizer-BMS, Boehringer-Ingelheim and Daiichi-Sankyo as well as fees for lectures from Pfizer-BMS, Boehringer-Ingelheim and Daiichi-Sankyo. All other authors declare that they have no competing interests.

Ethical approval The institutional review board of the LUMC, VUmc and MUMC approved the study protocol and waived the need for informed consent due to the observational design.

Open Access This article is distributed under the terms of the Creative Commons Attribution 4.0 International License (http://creativeco mmons.org/licenses/by/4.0/), which permits unrestricted use, distribution, and reproduction in any medium, provided you give appropriate credit to the original author(s) and the source, provide a link to the Creative Commons license, and indicate if changes were made. 


\section{References}

1. Enriquez-Sarano M, Schaff HV, Orszulak TA, Tajik AJ, Bailey KR, Frye RL (1995) Valve repair improves the outcome of surgery for mitral regurgitation. A multivariate analysis. Circulation 91(4):1022-1028

2. Moss RR, Humphries KH, Gao M, Thompson CR, Abel JG, Fradet G, Munt BI (2003) Outcome of mitral valve repair or replacement: a comparison by propensity score analysis. Circulation 108(Suppl 1):II90-I97. https://doi.org/10.1161/01.cir.0000089182 44963.bb

3. Chauvaud S, Fuzellier JF, Berrebi A, Deloche A, Fabiani JN, Carpentier A (2001) Long-term (29 years) results of reconstructive surgery in rheumatic mitral valve insufficiency. Circulation 104(12 Suppl 1):I12-I15

4. Russo A, Grigioni F, Avierinos JF, Freeman WK, Suri R, Michelena H, Brown R, Sundt TM, Enriquez-Sarano M (2008) Thromboembolic complications after surgical correction of mitral regurgitation incidence, predictors, and clinical implications. J Am Coll Cardiol 51(12):1203-1211. https://doi.org/10.1016/j. jacc.2007.10.058

5. Whitlock RP, Sun JC, Fremes SE, Rubens FD, Teoh KH, American College of Chest P (2012) Antithrombotic and thrombolytic therapy for valvular disease: antithrombotic therapy and prevention of thrombosis, 9th ed: American College of Chest physicians evidence-based clinical practice guidelines. Chest 141 (2 Suppl):e576S-e600S. https://doi.org/10.1378/chest.11-2305

6. Baumgartner H, Falk V, Bax JJ, De Bonis M, Hamm C, Holm PJ, Iung B, Lancellotti P, Lansac E, Munoz DR, Rosenhek R, Sjogren J, Tornos Mas P, Vahanian A, Walther T, Wendler O, Windecker S, Zamorano JL (2017) 2017 ESC/EACTS Guidelines for the management of valvular heart disease: The task force for the management of valvular heart disease of the European Society of Cardiology (ESC) and the European Association for CardioThoracic Surgery (EACTS). Eur Heart J 38(36):2739-2791. https ://doi.org/10.1093/eurheartj/ehx391

7. Nishimura RA, Otto CM, Bonow RO, Carabello BA, Erwin JP 3rd, Fleisher LA, Jneid H, Mack MJ, McLeod CJ, O'Gara PT, Rigolin VH, Sundt TM 3rd, Thompson A (2017) 2017 AHA/ACC focused update of the 2014 AHA/ACC Guideline for the management of patients with valvular heart disease: a report of the American College of Cardiology/American Heart Association task force on clinical practice guidelines. Circulation 135(25):e1159-e1195. https://doi.org/10.1161/CIR.0000000000000503

8. Aramendi JL, Agredo J, Llorente A, Larrarte C, Pijoan J (1998) Prevention of thromboembolism with ticlopidine shortly after valve repair or replacement with a bioprosthesis. J Heart Valve Dis 7(6):610-614

9. Deloche A, Jebara VA, Relland JYM, Chauvaud S, Fabiani JN, Perier P, Dreyfus G, Mihaileanu S, Carpentier A (1990) Valve repair with carpentier techniques - the 2 nd decade. J Thorac Cardiovasc Surg 99(6):990-1002

10. Jovin A, Hashim S, Jovin IS, Clancy JF, Klovekorn WP, MullerBerghaus G (2005) Atrial fibrillation at discharge from the hospital in patients undergoing mitral valve repair. Thorac Cardiovasc Surg 53(1):41-45. https://doi.org/10.1055/s-2004-830460

11. Braunberger E, Deloche A, Berrebi A, Abdallah F, Celestin JA, Meimoun P, Chatellier G, Chauvaud S, Fabiani JN, Carpentier A (2001) Very long-term results (more than 20 years) of valve repair with Carpentier's techniques in nonrheumatic mitral valve insufficiency. Circulation 104(12):I8-I1 1

12. Suri RM, Thourani VH, He X, Brennan JM, O'Brien SM, Rankin JS, Schaff HV, Gammie JS (2013) Variation in warfarin thromboprophylaxis after mitral valve repair: does equipoise exist and is a randomized trial warranted? Ann Thorac Surg 95(6):1991-1998. https://doi.org/10.1016/j.athoracsur.2013.03.024, discussion 1998-1999.

13. Vaughan P, Waterworth PD (2005) An audit of anticoagulation practice among UK cardiothoracic consultant surgeons following valve replacement/repair. J Heart Valve Dis 14(5):576-582

14. Kernis SJ, Nkomo VT, Messika-Zeitoun D, Gersh BJ, Sundt TM 3rd, Ballman KV, Scott CG, Schaff HV, Enriquez-Sarano M (2004) Atrial fibrillation after surgical correction of mitral regurgitation in sinus rhythm: incidence, outcome, and determinants. Circulation 110(16):2320-2325. https://doi.org/10.1161/01. CIR.0000145121.25259.54

15. Akins CW, Miller DC, Turina MI, Kouchoukos NT, Blackstone EH, Grunkemeier GL, Takkenberg JJM, David TE, Butchart EG, Adams DH, Shahian DM, Hagl S, Mayer JE, Lytle BW (2008) Guidelines for reporting mortality and morbidity after cardiac valve interventions. Eur J Cardiothorac Surg 33(4):523-528. https ://doi.org/10.1016/j.ejcts.2007.12.055

16. Schulman S, Angeras U, Bergqvist D, Eriksson B, Lassen MR, Fisher W, Subcommittee on Control of Anticoagulation of the S, Standardization Committee of the International Society on T, Haemostasis (2010) Definition of major bleeding in clinical investigations of antihemostatic medicinal products in surgical patients. J Thromb Haemost 8(1):202-204. https://doi.org/10.11 11/j.1538-7836.2009.03678.x

17. Takkenberg JJM, Puvimanasinghe JPA, van Herwerden LA, Steyerberg EW, Eijkemans MJC, Habbema JDF, Bogers AJJC (2001) Prognosis after aortic valve replacement with St. Jude Medical bileaflet prostheses: impact on outcome of varying thromboembolic and bleeding hazards. Eur Heart J 3(Suppl Q):Q27-Q32. https://doi.org/10.1016/S1520-765x(01)90039-2

18. Meurin P, Tabet JY, Iliou MC, Pierre B, Corone S, Cristofini P, Iung B, Ben Driss A, Working Group of Cardiac Rehabilitation of the French Society of C (2008) Thromboembolic events early after mitral valve repair: incidence and predictive factors. Int J Cardiol 126(1):45-52. https://doi.org/10.1016/j.ijcard.2007.03.115

19. Paparella D, Di Mauro M, Worms KB, Bolotin G, Russo C, Trunfio S, Scrofani R, Antona C, Dato GA, Casabona R, Colli A, Gerosa G, Renzulli A, Serraino F, Scrascia G, Zaccaria S, De Bonis M, Taramasso M, Delgado L, Tritto F, Marmo J, Parolari A, Myaseodova V, Villa E, Troise G, Nicolini F, Gherli T, Whitlock R, Conte M, Barili F, Gelsomino S, Lorusso R, Sciatti E, Marinelli D, Di Giammarco G, Calafiore AM, Sheikh A, Alfonso JJ, Glauber M, Miceli A, Investigators G (2016) Antiplatelet versus oral anticoagulant therapy as antithrombotic prophylaxis after mitral valve repair. J Thorac Cardiovasc Surg 151(5):1302-1308. https://doi.org/10.1016/j.jtcvs.2015.12.036

20. Thourani VH, Gunter RL, Hurst S, Kilgo P, Padala M, Puskas JD, Lattouf OM, Halkos ME, Guyton RA (2013) Postoperative warfarin following mitral valve repair or bioprosthetic valve replacement. J Heart Valve Dis 22(5):716-723

21. Nishimura RA, Otto CM, Bonow RO, Carabello BA, Erwin JP 3rd, Guyton RA, O'Gara PT, Ruiz CE, Skubas NJ, Sorajja P, Sundt TM 3rd, Thomas JD, American College of Cardiology/ American Heart Association Task Force on Practice G (2014) 2014 AHA/ACC guideline for the management of patients with valvular heart disease: executive summary: a report of the American College of Cardiology/American Heart Association task force on practice guidelines. J Am Coll Cardiol 63(22):2438-2488. https://doi.org/10.1016/j.jacc.2014.02.537

22. Schwann TA, Engoren M, Bonnell M, Clancy C, Khouri S, Kabour A, Jamil T, Habib RH (2013) Mitral valve repair and bioprosthetic replacement without postoperative anticoagulation does not increase the risk of stroke or mortality. Eur J Cardiothorac Surg 44(1):24-31. https://doi.org/10.1093/ejcts/ezs626

23. Khuri SF, Wolfe JA, Josa M, Axford TC, Szymanski I, Assousa S, Ragno G, Patel M, Silverman A, Park M, Valeri CR (1992) 
Hematologic changes during and after cardiopulmonary bypass and their relationship to the bleeding-time and nonsurgical bloodloss. J Thorac Cardiovasc Surg 104(1):94-107

24. Salis S, Mazzanti VV, Merli G, Salvi L, Tedesco CC, Veglia F, Sisillo E (2008) Cardiopulmonary bypass duration is an independent predictor of morbidity and mortality after cardiac surgery. J Cardiothorac Vasc Anesth 22(6):814-822. https://doi. org/10.1053/j.jvca.2008.08.004
25. Asher CR, Miller DP, Grimm RA, Cosgrove DM 3rd, Chung MK (1998) Analysis of risk factors for development of atrial fibrillation early after cardiac valvular surgery. Am J Cardiol 82(7):892-895

26. Renda G, Ricci F, Giugliano RP, De Caterina R (2017) Non-vitamin $\mathrm{K}$ antagonist oral anticoagulants in patients with atrial fibrillation and valvular heart disease. J Am Coll Cardiol 69(11):13631371. https://doi.org/10.1016/j.jacc.2016.12.038 